\title{
Ommastrephid squids Sthenoteuthis oualaniensis and Dosidicus gigas in the eastern Pacific show convergent biogeographic breaks but contrasting population structures
}

\author{
Danna J. Staaif ${ }^{1, *}$, R. I. Ruiz-Cooley ${ }^{2}$, Carl Elliger ${ }^{1}$, Zora Lebaric ${ }^{1}$, \\ Bernardita Campos ${ }^{3}$, Unai Markaida ${ }^{4}$, William F. Gilly ${ }^{1}$ \\ ${ }^{1}$ Hopkins Marine Station of Stanford University, Oceanview Blvd, Pacific Grove, California 93950, USA \\ ${ }^{2}$ Protected Resources Division, Southwest Fisheries Science Center, National Marine Fisheries Service, NOAA, \\ 3333 North Torrey Pines Court, La Jolla, California 92037, USA \\ ${ }^{3}$ Facultad de Ciencias del Mar y de Recursos Naturales, Universidad de Valparaíso, Valparaíso, PO Box 5080, Reñaca, \\ Viña del Mar, Chile \\ ${ }^{4}$ Línea de Pesquerías Artesanales, El Colegio de la Frontera Sur, CONACYT, Calle 10 \#264, 24000 Campeche, Mexico
}

\begin{abstract}
Dosidicus gigas and Sthenoteuthis oualaniensis (Teuthoidea: Ommastrephidae: Ommastrephinae) are abundant, ecologically important squid that co-occur in the eastern tropical Pacific. Little is known about the genetic basis of population structure in either species, although the presence of 2 species within $S$. oualaniensis has been suggested. We report here on a comparative population genetic study of $D$. gigas and $S$. oualaniensis using the mitochondrial marker NADH dehydrogenase subunit 2 . Despite the high potential for dispersal in these active swimmers, both species exhibit a distinct biogeographic break at 5 to $6^{\circ} \mathrm{N}$. S. oualaniensis contains multiple deeply divergent, geographically segregated clades, whereas $D$. gigas shows only mild divergence between northern and southern hemisphere populations. We suggest that dispersal and genetic mixing across the eastern tropical Pacific may be impeded by both oceanographic and ecological factors.
\end{abstract}

KEY WORDS: Biogeographic comparison · Eastern Pacific $\cdot$ Ommastrephid squid · Population genetic structure

\section{INTRODUCTION}

Ommastrephid squid are large, abundant predators in pelagic ecosystems. Their population structures are often complex and contain different size-at-maturity groups which overlap geographically (Nesis 1993). A clearer picture of ommastrephid population genetics is necessary to understand their ecological roles and to implement fishery management strategies for species of commercial importance.

The largest ommastrephid, commonly known as the Humboldt or jumbo (flying) squid (Dosidicus gigas Orbigny, 1835), supports one of the largest inverte- brate fisheries in the world $(818000 \mathrm{t}$ in 2006 and $670000 \mathrm{t}$ in 2007; FAO 2010). Its range stretches from $30^{\circ} \mathrm{N}$ to $25^{\circ} \mathrm{S}$, with occasional forays to $40^{\circ} \mathrm{N}$ and $47^{\circ} \mathrm{S}$ (Nigmatullin et al. 2001) and a recent extension to $60^{\circ} \mathrm{N}$ (Cosgrove 2005, Wing 2006) (Fig. 1). Within this range, 3 different forms of $D$. gigas have been recognized based on mantle length (ML) at maturity (Nigmatullin et al. 2001; our Table 1). The 'medium' size-atmaturity form occurs across the entire species range. A 'small' size-at-maturity form is thought to be limited to equatorial waters, and the northern and southern peripheries of the species range are inhabited by a 'large' size-at-maturity form which can exceed $100 \mathrm{~cm}$ 


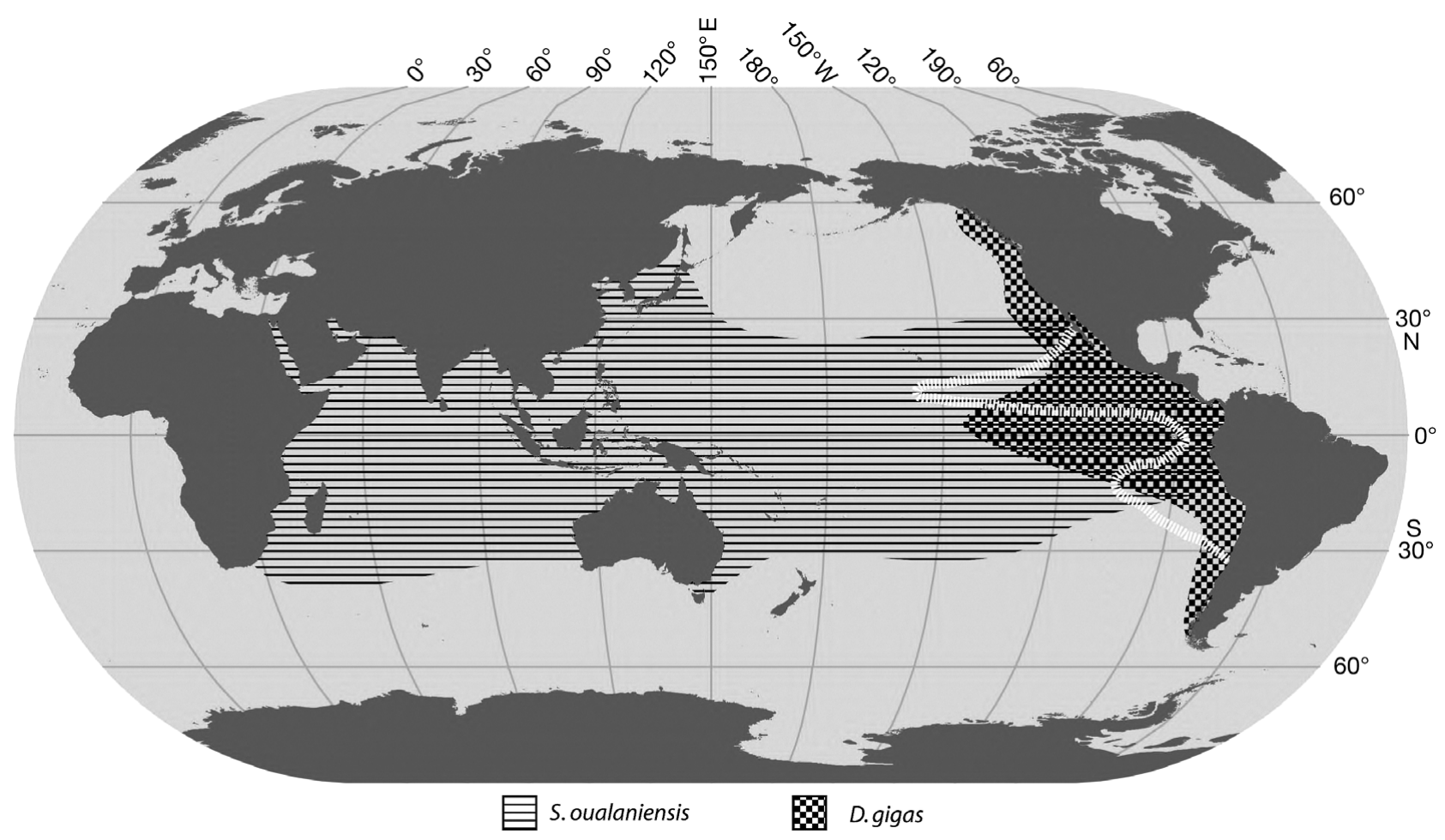

Fig. 1. Dosidicus gigas and Sthenoteuthis oualaniensis. Species ranges illustrating the region of overlap (adapted from Roper et al. 1984). Eastern Pacific oxygen minimum zone is shown by a hashed white line, indicating $20 \mu \mathrm{M}$ dissolved oxygen at $300 \mathrm{~m}$ depth (data from Garcia et al. 2006)

Table 1. Dosidicus gigas and Sthenoteuthis oualaniensis. Size-at-maturity forms (Nesis 1983, Dunning 1998, Nigmatullin et al. 2001). ML: mantle length. nd: no morphological differences other than size at maturity are known for the forms of $D$. gigas

\begin{tabular}{|lclc|}
\hline Species & $\begin{array}{c}\text { Size at maturity } \\
(\mathrm{ML} ; \mathrm{cm})\end{array}$ & \multicolumn{1}{c|}{ Range } & Morphology \\
\hline D. gigas & $13-34$ & Equatorial (tropical) & nd \\
& $24-60$ & Entire species range & nd \\
& $40-65$ & Non-equatorial (temperate) & nd \\
S. oualaniensis & $9-12$ & Equatorial & No photophore $^{\mathrm{a}}$ \\
& $12-25$ & Entire species range & Photophore $^{\mathrm{a}}$ \\
& $40-50$ & North Indian Ocean & Photophore \\
a These morphologies demonstrate 2 distinct gladius structures in western \\
specimens
\end{tabular}

ML. Nigmatullin et al. (2001) suggested that the 3 sizeat-maturity forms may be incipient species, or at least distinct stocks. However, other researchers have proposed separating D. gigas into only 2 stocks, one 'northern' and one 'southern,' based on supposed migration patterns rather than size at maturity (Wormuth 1976, 1998, Nesis 1983, Clarke \& Paliza 2000).

Tagging studies on individuals of the large form of Dosidicus gigas have revealed that they make extensive use of the prominent oxygen minimum zone
(OMZ) in the eastern Pacific, indicated with a white hashed line in Fig. 1. This zone provides a refuge from predators that cannot tolerate hypoxia, and also appears to be a favored hunting area of these large D. gigas (Gilly et al. 2006b).

In the eastern tropical Pacific, the range of Dosidicus gigas overlaps with that of Sthenoteuthis oualaniensis (Lesson, 1830), the purpleback flying squid, a species of growing commercial interest ( $\mathrm{Zu}$ yev et al. 2002, Xinjun et al. 2007). $S$. oualaniensis, however, does not extend into the temperate Pacific but it is found across the tropical and subtropical Pacific and Indian Oceans (Fig. 1). This transoceanic range is typical of the subfamily Ommastrephinae, to which both species belong. The northsouth distribution of $D$. gigas is unique and may belie an ecological connection between this species and the OMZ.

Sthenoteuthis oualaniensis comprises multiple forms (Nesis 1983, Dunning 1998) (Table 1), varying both in size at maturity and in the possession of a distinctive large dorsal photophore. A middle-sized 'typical' form 
with the photophore is found throughout the species range and co-occurs with Dosidicus gigas in the eastern tropical Pacific. Equatorial waters of the Indian and Pacific Oceans $\left(10-15^{\circ} \mathrm{N}\right.$ to $\left.10-15^{\circ} \mathrm{S}\right)$ are inhabited by an 'early-maturing' dwarf form that lacks the dorsal photophore and may constitute a separate, as yet undescribed, species (Clarke 1965, 1966, Nigmatullin et al. 1983a, Nesis 1993).

In the western part of the range of Sthenoteuthis oualaniensis, detailed studies have revealed greater complexity. The middle-sized and dwarf forms may each contain 2 groups with distinct gladius structures, and the middle-sized form can have 2 different sizes at maturity (Nesis 1993). Perhaps most striking, a giant form of $S$. oualaniensis was documented in the western Indian Ocean north of 15 to $17^{\circ} \mathrm{N}$ (Nesis 1993). Like the large form of Dosidicus gigas, this giant $S$. oualaniensis is associated with a prominent OMZ. Snÿder (1998) suggested that this form may arise through phenotypic plasticity, a feature that may facilitate the best use of available resources associated with the OMZ. However, Zuyev et al. (2002) proposed that the various forms of $S$. oualaniensis are indicative of active sympatric and allopatric speciation, facilitated by the high fecundity and rapid generational turnover common to all ommastrephid squid.

Indeed, variation in size at maturity within both Sthenoteuthis oualaniensis and Dosidicus gigas has been attributed at different times and by different researchers to genetic substructure or phenotypic plasticity. Genetic assertions remain speculative, however, due to limited molecular studies. The only molecular work on S. oualaniensis used allozymes from Indian Ocean samples to support the hypothesis that the dwarf photophore-less form is a separate species, while suggesting that middle-sized and giant forms might be considered 'local groups' (Yokawa \& Jerez 1999). As for D. gigas, isozyme analysis indicated that the 3 size-groups from Peruvian waters belong to the same population (Yokawa 1995). Sandoval-Castellanos et al. (2007) distinguished northern and southern genetic populations of $D$. gigas with randomly amplified polymorphic DNA from 8 near-shore sites from approximately $30^{\circ} \mathrm{N}$ to $35^{\circ} \mathrm{S}$. However, these authors (Sandoval-Castellanos et al. 2010) did not find further support for the north-south structure in cytochrome $b$ sequences.

The present study is a comparative genetic analysis of Dosidicus gigas and Sthenoteuthis oualaniensis using mitochondrial sequence data from specimens collected over much of the eastern Pacific, including the region of range overlap and the recent northward expansion of D. gigas. We aim to test the hypotheses that different size-at-maturity forms comprise genetically distinct units and that genetic structure follows geographic patterns. The present study is the first genetic analysis of $S$. oualaniensis in the eastern Pacific Ocean and the first genetic sampling of $D$. gigas throughout its range.

\section{MATERIALS AND METHODS}

Sample collection. Tissue samples were taken from 802 individual specimens of Dosidicus gigas collected between 1999 and 2008 from 53 locations throughout this species' range (Table $\mathrm{S} 1$ in the Supplement at www.int-res.com/articles/suppl/m418p165_supp.pdf) and pooled into 23 samples (Table 2), as described below under 'Analysis'. Individual samples $(n=107)$ of Sthenoteuthis oualaniensis were collected from 40 locations between 2003 and 2007 in the central and eastern Pacific (Table 3).

Squid were obtained by jigging, from beach strandings, with dip nets (small juveniles), or in bongo net tows (paralarvae). Either muscle or gill tissue was sampled for molecular work. Small pieces of gill $\left(\sim 0.5 \mathrm{~cm}^{3}\right)$ were dissected and preserved in $90 \%$ ethanol. Muscle samples were taken from adults and juveniles by cutting 1 to $2 \mathrm{~cm}$ of tissue off an arm tip with subsequent preservation in $70 \%$ ethanol. In some cases, the entire animal was frozen, and the arm tip sampled at a later date. Small paralarvae were used in their entirety for DNA extraction; only the posterior part of the mantle of larger paralarvae was used.

Dorsal ML was measured for adult squid from a subset of the geographic locations sampled. Sex and sexual maturity of these specimens was visually assessed (Lipiński \& Underhill 1995). ML and sexual maturity from a subset of specimens were used to identify forms for each species as described in Table 1.

DNA isolation, PCR amplification, and sequencing. DNA was extracted, typically from about $25 \mathrm{mg}$ of tissue, using the Qiagen DNeasy Tissue/Blood Kit. The quality and quantity of DNA was not affected by the type of tissue or length of time that the sample was kept frozen or in ethanol. However, we did find that carcasses in Baja California Sur, México, which remained at ambient air temperatures in excess of $\sim 30^{\circ} \mathrm{C}$ without preservation for more than $\sim 6 \mathrm{~h}$ tended to yield degraded DNA. The concentration for use as a PCR template was adjusted to an $A_{260}$ of about 0.05 to 0.2 .

The complete mitochondrial genomes of 4 individuals (1 Dosidicus gigas, 3 Sthenoteuthis oualaniensis) were sequenced using PCR primers designed from highly conserved regions of transfer RNA (tRNA) sequences of related species (Yokobori et al. 2004) with additional specific primers designed as required from sequences already obtained. PCR amplifications were carried out using TAKARA ExTaq HS DNA polymerase in $50 \mu \mathrm{l}$ volumes, taking $1 \mu \mathrm{l}$ of template ac- 
Table 2. Dosidicus gigas. Pooled sampling locations and dates, ordered by latitude from north to south. Total of 802 sequences. $\mathrm{n}$ : number of individuals from each location. Hap: number of haplotypes identified from that group. RBCM: Royal British Columbia Museum. GC: Gulf of California

\begin{tabular}{|c|c|c|c|c|c|}
\hline Location & Date & Latitude $\left({ }^{\circ} \mathrm{N}\right.$ or $\left.{ }^{\circ} \mathrm{S}\right)$ & Longitude $\left({ }^{\circ} \mathrm{W}\right)$ & $\mathrm{n}$ & Hap \\
\hline Alaska and Canada & $2004-2005$ & $56.94667^{\circ} \mathrm{N}$ & 135.75000 & 4 & 3 \\
\hline Canada '08 & 2008 & $58.81373^{\circ} \mathrm{N}$ & 133.63057 & 15 & 11 \\
\hline RBCM, Canada & $2004-2005$ & $48.88833^{\circ} \mathrm{N}$ & 125.58500 & 12 & 11 \\
\hline Oregon, USA & 2005 and 2007 & $45.61058^{\circ} \mathrm{N}$ & 123.94430 & 21 & 17 \\
\hline Cordell Bank, California, USA & Dec 2006 & $37.86683^{\circ} \mathrm{N}$ & 123.51267 & 16 & 16 \\
\hline Monterey, California, USA & Nov 2004 & $36.33000^{\circ} \mathrm{N}$ & 122.90000 & 30 & 28 \\
\hline Pacific off Mexico 1 & Aug 2005 & $31.91380^{\circ} \mathrm{N}$ & 118.65820 & 7 & 6 \\
\hline Ensenada, Pacific, Mexico & Sep 1999 & $31.83333^{\circ} \mathrm{N}$ & 116.61667 & 12 & 14 \\
\hline GC, Mexico '99 & 1999 & $27.55879^{\circ} \mathrm{N}$ & 112.40106 & 32 & 26 \\
\hline GC, Mexico '04-'06 & $2004-2006$ & $27.55879^{\circ} \mathrm{N}$ & 112.40106 & 318 & 220 \\
\hline Pacific off Mexico 2 & Sep 2004 & $26.36583^{\circ} \mathrm{N}$ & 114.05833 & 17 & 16 \\
\hline Pacific off Mexico 3 & Sep 2005 & $25.83333^{\circ} \mathrm{N}$ & 117.12028 & 11 & 11 \\
\hline Topolobampo, GC, Mexico & May 1999 & $25.60383^{\circ} \mathrm{N}$ & 109.04641 & 15 & 10 \\
\hline Magdalena Bay, GC, Mexico & Jun 2005 & $24.57839^{\circ} \mathrm{N}$ & 111.99979 & 30 & 24 \\
\hline Southern GC, Mexico & Jun 2005 & $23.58617^{\circ} \mathrm{N}$ & 108.87283 & 39 & 27 \\
\hline Mexico & 2006 & $21.79533^{\circ} \mathrm{N}$ & 109.304 & 6 & 6 \\
\hline Southern Mexico & Oct 2006 & $14.40783^{\circ} \mathrm{N}$ & 94.922 & 7 & 7 \\
\hline Costa Rica Dome & Sep 2006 & $7.48083^{\circ} \mathrm{N}$ & 85.02194 & 7 & 5 \\
\hline Eastern tropical Pacific & Oct 2006 & $4.71667^{\circ} \mathrm{S}$ & 97.55000 & 90 & 38 \\
\hline Peru '07 & $2006-2007$ & $5.51635^{\circ} \mathrm{S}$ & 81.51822 & 27 & 14 \\
\hline Peru '06 & Dec 2006 & $8.77400^{\circ} \mathrm{S}$ & 79.57917 & 27 & 13 \\
\hline Chile '05 & May 2005 & $33.05000^{\circ} \mathrm{S}$ & 71.66670 & 28 & 16 \\
\hline Chile '06 & Aug 2006 & $38.65000^{\circ} \mathrm{S}$ & 73.91667 & 31 & 18 \\
\hline
\end{tabular}

Table 3. Sthenoteuthis oualaniensis. Sampling locations and dates. Total of 107 sequences. n: number of individuals sampled at each location. Hap: number of haplotypes identified from that group. Latitude and longitude not included as a large area was covered in each location-see Fig. 6 for marked sampling sites

\begin{tabular}{|lccc|}
\hline Location & Date & $\mathrm{n}$ & Hap \\
\hline Eastern tropical Pacific & Oct 2006 & 53 & 12 \\
Central tropical Pacific & 2003 & 1 & 1 \\
Central tropical Pacific & May 2005 & 14 & 13 \\
Central tropical Pacific & May 2007 & 33 & 27 \\
\hline
\end{tabular}

cording to the manufacturer's recommendations. Extension times were 3 to 4 min, depending on amplicon length. PCR products were purified by use of the Qiagen Qiaquick Kit or with the Machery Nagel Nucleospin Extract II Kit. Sequence data were obtained using an ABI PRISM 3100 genetic automatic sequencer and Big Dye v. 1.3 dye terminator chemistry. Sequencing primers are shown in Tables S2 to S11 in the Supplement at www.int-res.com/articles/suppl/m418 p165_supp.pdf. Sequence analysis and assembly were completed in Gene Works v. 2.0 (Intelligenetics) or Sequencher v. 4.7 (Gene Codes Corporation).

Sequencing for population genetics used 3 markers: (1) cytochrome $c$ oxidase subunit 1 (COI), (2) a noncoding region (NCR2) located between tRNA-Glu and cytochrome $c$ oxidase subunit 3 (CO3, copy 1$)$, and (3) the NADH dehydrogenase subunit 2 (ND2) region. For reasons described below ('Analysis'), the analysis in the present paper is focused on ND2.

A 658 nucleotide (nt) fragment (exclusive of primers) of COI was generated using the forward primer LCO1490 (Tables S2 \& S5 in the Supplement) and reverse primer HCO 2198 (Tables S3 \& S6 in the Supplement) for both species (Folmer et al. 1994). PCR of the NCR2 (558 nt in Dosidicus gigas, and $563 \mathrm{nt}$ in Sthenoteuthis oualaniensis) marker was performed with the forward primer DGEF (both species; Tables S2 \& S5 in the Supplement) and the reverse primers SqCO3R (both species; Tables S3 \& S6 in the Supplement) and RSqI (S. oualaniensis; Table S6 in the Supplement). PCR of the ND2 marker (1041 nt) was performed with the following primers: SqSF forward (both species; Tables S2 \& S5 in the Supplement), DCOR2 reverse (D. gigas; Table S3 in the Supplement), SCOR reverse (S. oualaniensis; Table S6 in the Supplement).

PCR amplification for these regions used 2.5 units of Biolase DNA polymerase (Bioline USA) in $100 \mu \mathrm{l}$ volumes using $1 \mu \mathrm{l}$ of template with $2 \mathrm{mM} \mathrm{MgCl}_{2}, 200 \mu \mathrm{M}$ dNTPs, and primers at $250 \mathrm{nM}$. After $7 \mathrm{~min}$ at $94^{\circ} \mathrm{C}$, the reactions were subjected to 40 cycles of $94^{\circ} \mathrm{C}(10 \mathrm{~s})$, $46^{\circ} \mathrm{C}$ (30 s), a gradient of $6^{\circ} \mathrm{C} \mathrm{s}^{-1}$ to $72^{\circ} \mathrm{C}$, and $72^{\circ} \mathrm{C}$ (1.00 $\mathrm{min}$ ) followed by a final extension of $7 \mathrm{~min}$ at $72^{\circ} \mathrm{C}$. Sequencing of purified PCR products used the amplification primers. 
The complete mitochondrial genome of Dosidicus gigas is stored in GenBank (accession no. NC009734). Complete mitochondrial genomes of 3 major clades of Sthenoteuthis oualaniensis are also stored in GenBank: Pacific Typical (accession no. NC010636), Equatorial (accession no. EU660577), and Eastern Typical (accession no. EU658923) (see 'Results' for explanation of clades). The 3 mitochondrial markers, ND2, COI, and NCR, are included in these complete genomes. Several additional $D$. gigas ND2 sequences have also been deposited (accession nos. FJ153071, FJ153073, FJ153075, and EF025502).

Analysis. The mitochondrial genomes of both Dosidicus gigas and Sthenoteuthis oualaniensis contain duplicated regions that include genes for cytochrome $c$ oxidase subunits 1 to 3, tRNA-Asp, ATP synthetase subunits 6 and 8, as well as a long NCR of about 565 nt. Thus, analyses of COI and NCR markers suffer from the complications associated with duplicate copies. In addition, the NCRs of $D$. gigas and $S$. oualaniensis contain numerous insertions and deletions as well as AT (adenine-thymine)-rich regions of variable length, features that complicate analysis.

Therefore, for the purposes of the present study, we chose to focus on the gene for ND2 that occurs as a single copy in both species, obviating the need for concern over which copy is being amplified and sequenced. Although we present results only from ND2, our preliminary analysis of a subset of COI sequences confirmed the patterns reported here (data not shown).

Maximum-likelihood phylogenetic trees were constructed for both Dosidicus gigas and Sthenoteuthis oualaniensis in PhyML (Guindon \& Gascuel 2003). The search started with a neighbor-joining tree, used the nearest-neighbor interchange (NNI) search method, optimized both topology and branch lengths, and computed approximate liklihood-ratio test (aLRT) for branch support. One sequence of each species was used as outgroup for the other. Optimal nucleotide substitution models for maximum likelihood were calculated with Akaike's Information Criterion (AIC) in jMODELTEST (Posada 2008) (TrN + I for D. gigas and $\mathrm{TIM}+$ I for $S$. oualaniensis where $\operatorname{TrN}=$ Tamura-Nei, TIM = Transition model, and I indicates the inclusion of a proportion of invariable sites; Tamura \& Nei 1993, Rodríguez et al. 1990). As TIM is not implemented in PhyML, the next best option, GTR + I, was used for $S$. oulaniensis, where GTR = General Time Reversible.

Due to the large size of the Dosidicus gigas sample set $(\mathrm{n}=802)$, bootstrapping attempts proved excessively time-intensive, and as obvious clades were not present, we chose not to pursue this avenue. For Sthenoteuthis oualaniensis, in which clear clades were present, clade support was assessed with 1000 bootstrap replicates. Arlequin (Excoffier et al. 2005) was used to calculate average pairwise genetic distances between and within the clades, by calculating the number of (corrected average) pairwise differences and dividing this by the total number of loci (1027).

Pairwise genetic distances between the 57 sampled locations for Dosidicus gigas were calculated as Slatkin's linearized pairwise $F_{\text {st }}$ (Slatkin 1995) with Arlequin. Locations with $<15$ ind. that were within $6^{\circ}$ of each other, and did not have a significant $(p<0.05)$ pairwise $F_{\text {st, }}$ were pooled. The Baja California area (22 to $32^{\circ} \mathrm{N}$ ) was more densely sampled than the remainder of the study area, and different criteria were used for pooling in this region. A large number of samples were taken in 1999, after a strong El Niño. These were kept separate from the remaining samples, taken in 2004 to 2006. Any 2004-2006 locations within $2^{\circ}$ of each other that did not have a significant $(\mathrm{p}<0.05)$ pairwise $F_{\text {st }}$ were pooled. This resulted in a total of 23 pooled samples (Table 2). Hierarchical analysis of molecular variance (AMOVA) (Weir \& Cockerham 1984, Weir 1996) on this pooled D. gigas data set was performed in Arlequin using the Kimura 2P substitution model (Kimura 1980) and 1000 permutations.

Having discerned 2 distinct populations from pairwise $F_{\text {st }}$ values, we used the Isolation with Migration (IM) computer program (Hey \& Nielsen 2004) to fit the data to a coalescent model of 2 populations diverging from 1 ancestral population and exchanging migrants. This program estimates the effective population sizes (female only, as the data are mitochondrial) of the northern population, the southern population, and the ancestral population; the migration rates from north to south, and from south to north; and the time since divergence, all scaled to the neutral mutation rate.

Due to the large number of samples, the program did not converge with the complete data set, so it was run on 4 random subsamples of 50 sequences from each population (north and south, total 100). We assigned broad prior distributions based on preliminary trial runs, and implemented Metropolis coupling with 30 chains and a geometric heating model with parameters of 0.8 and 0.9 . We used a burn-in period of 200000 steps and ran the program for 5000000 steps, recording results every 100 steps. The Hasegawa-KishinoYano (HKY) mutation model was used, as it is the only model appropriate for mitochondrial data implemented in IM. Convergence was assessed by running each subsample 3 times under identical conditions with different random number seeds. All 3 runs gave extremely similar parameter estimates in each of the 4 cases. The lowest effective sample size for any parameter (ESS; see Hey \& Nielsen 2004) was 8732, and most were $>10000$. 
Mitochondrial mutation rates for cephalopods are not available, so we followed Donald et al. (2005) in using a molluscan range from $0.7 \%$ (gastropod Tegula; Hellberg \& Vacquier 1999) to $2.4 \%$ (arcid bivalves; Marko 2002). The IM estimate of time since divergence is given in generations, but the generation time of Dosidicus gigas is 1 yr (Markaida et al. 2004), so no arithmetic was necessary to convert from generations to years.

Degree of association between genetic distance and geographic distance in Dosidicus gigas was quantified with a Mantel test (Mantel 1967, Sokal \& Rohlf 1995), implemented in Arlequin. Pairwise genetic distances were calculated as Slatkin's linearized pairwise $F_{\text {st }}$ (Slatkin 1995). Geographic distances were calculated from latitude and longitude with the Geographic Distance Matrix Generator (Ersts 2009), which assumes the earth is a sphere and uses great circles to calculate distance. This method does not take coastlines into account, such that the distance between 2 points on opposite sides of the Baja Peninsula is the overland route, which is clearly not available to a traveling squid. As this unrealistic calculation is of primary concern in the Baja region, and pairwise genetic comparisons between Pacific Baja samples and Gulf Baja samples showed no significant differences (see 'Results'), we accept the approximation.

\section{RESULTS}

\section{Dosidicus gigas}

AMOVA of the data set gave a significant $(\mathrm{p}<0.05)$ $F_{\text {ST }}$ of 0.05161 , indicating some partitioning of genetic variation between samples. Pairwise genetic distance plotted against geographic distance (Fig. 2) gave an $\mathrm{r}^{2}$ value of 0.3148 , which was significant according to a Mantel test. This could indicate an isolation-by-distance pattern of genetic variation.

However, pairwise $F_{\mathrm{ST}}$ values between samples showed that the samples from the 5 southernmost sampling sites were significantly different from most of the other samples, and not significantly different from each other (Table 4). This suggests that the driving force behind the significant $F_{\mathrm{ST}}$ of the overall data set was a simple north-south divergence. Indeed, AMOVA of either the northern samples alone or the southern samples alone gave a non-significant $F_{\mathrm{ST}}$ value (northern: -0.00456 , southern: 0.00950, p > 0.05). Imposing a 2-group geographic structure on the data set (Fig. 3) and implementing a hierarchical AMOVA resulted in a significant $F_{\mathrm{ct}}$ assigning $11.05 \%$ of genetic variation to variability between these 2 groups.

IM estimates of divergence time between the north and south populations ranged from $133000 \pm 12000$

Table 4. Dosidicus gigas. Pairwise $F_{\mathrm{ST}}$ between 23 pooled populations, calculated with Kimura 2P. Values in bold are significant (p < 0.05). AKCA: Alaska and Canada; CA: Canada; RBCM: Royal British Columbia Museum; OR: Oregon; COR: Cordell Bank; MBARI: Monterey Bay Aquarium Research Institute Collections; PAC1: Pacific off Mexico 1; ENSE: Ensenada; GC99: Gulf of California, 1999; GC04: Gulf of California, 2004-2006; PAC2: Pacific off Mexico 2; PAC3: Pacific off Mexico 3; TOP: Topolobampo; MAG: Magdalena Bay; SOU: southern Gulf of California; MEX: Mexico; SMEX: southern Mexico; CR: Costa Rica Dome; ETP: eastern tropical Pacific; Per07: Peru, 2006-2007; Per06: Peru, Dec 2006; Chi05: Chile, May 2005; Chi06: Chile, Aug 2006

AKCA CA RBCM OR COR MBARI PAC1 ENSE GC99 GC04 PAC2 PAC3 TOP MAG SOU MEX SMEX CR ETP Per07 Per06 Chi05 Chi06

AKCA $\quad 0.000$

CA $\quad 0.131 \quad 0.000$

RBCM $\quad 0.058-0.0060 .000$

$\begin{array}{llllll}\mathrm{OR} & 0.056 & 0.001 & -0.018 & 0.000\end{array}$

COR $\quad 0.029-0.026-0.012-0.0100 .000$

MBARI $0.047 \quad 0.007-0.005-0.022-0.004 \quad 0.000$

$\begin{array}{lllllll}\text { PAC1 } & \mathbf{0 . 2 0 7} & -0.052-0.035 & 0.008 & -0.022 & 0.017 & 0.000\end{array}$

ENSE $\quad-0.060 \quad 0.002-0.030-0.047-0.043-0.048 \quad 0.034 \quad 0.000$

GC99 $0.071-0.026-0.046-0.025-0.056-0.007-0.029-0.0290 .000$

GC04 $0.041-0.015-0.019-0.035-0.017-0.015-0.013-0.036-0.0380 .000$

$\begin{array}{llllll}\text { PAC2 } & 0.071 & 0.014-0.034-0.034 & 0.003-0.019 & 0.006-0.034-0.015-0.030 & 0.000\end{array}$

PAC3 $\quad 0.024 \quad 0.023-0.015-0.031-0.006-0.029 \quad 0.022-0.063-0.008-0.023-0.0360 .000$

TOP $\quad 0.037 \quad 0.001-0.001-0.025-0.012-0.020 \quad 0.011-0.043-0.024-0.028-0.020-0.0240 .000$

MAG $\quad 0.019-0.028-0.072-0.039-0.049-0.016-0.022-0.064-0.079-0.056-0.048-0.049-0.0350 .000$

SOU $\quad 0.093-0.024-0.006-0.009-0.0150 .009-0.019-0.003-0.027-0.0360 .001 \quad 0.012-0.009-0.0330 .000$

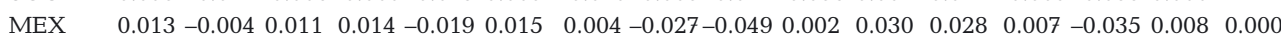

SMEX $\quad 0.040-0.013-0.003-0.008-0.014 \quad 0.003-0.017-0.022-0.043-0.0190 .000 \quad 0.004-0.006-0.045-0.012 \quad 0.001 \quad 0.000$

CR $\quad \begin{array}{lllllllllllllll}0.030 & -0.012 & 0.000 & 0.002 & -0.011 & 0.017 & -0.020-0.013-0.057-0.020 & 0.010 & 0.012 & 0.002 & -0.055 & -0.019-0.004-0.004 & 0.000\end{array}$

$\begin{array}{llllllllllllllllllll}\text { ETP } & 0.426 & 0.254 & 0.160 & 0.193 & 0.231 & 0.204 & 0.239 & 0.293 & 0.222 & 0.218 & 0.161 & 0.235 & 0.202 & 0.191 & 0.246 & 0.220 & 0.114 & 0.202 & 0.000\end{array}$

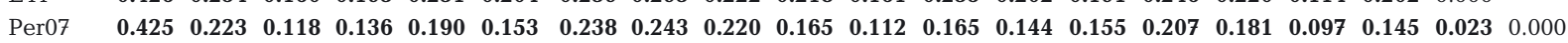

$\begin{array}{lllllllllllllllllllllllllll}\text { Per06 } & 0.318 & 0.174 & 0.083 & 0.120 & 0.138 & 0.121 & 0.175 & 0.181 & 0.154 & 0.131 & 0.093 & 0.145 & 0.124 & 0.122 & 0.167 & 0.132 & 0.084 & 0.124 & 0.006 & 0.066 & 0.000\end{array}$

$\begin{array}{llllllllllllllllllllllll}\text { Chi05 } & 0.305 & 0.176 & 0.092 & 0.112 & 0.141 & 0.123 & 0.180 & 0.170 & 0.151 & 0.131 & 0.090 & 0.127 & 0.122 & 0.103 & 0.164 & 0.144 & 0.086 & 0.126 & -0.003 & 0.018 & 0.003 & 0.000\end{array}$

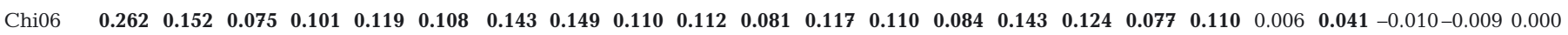




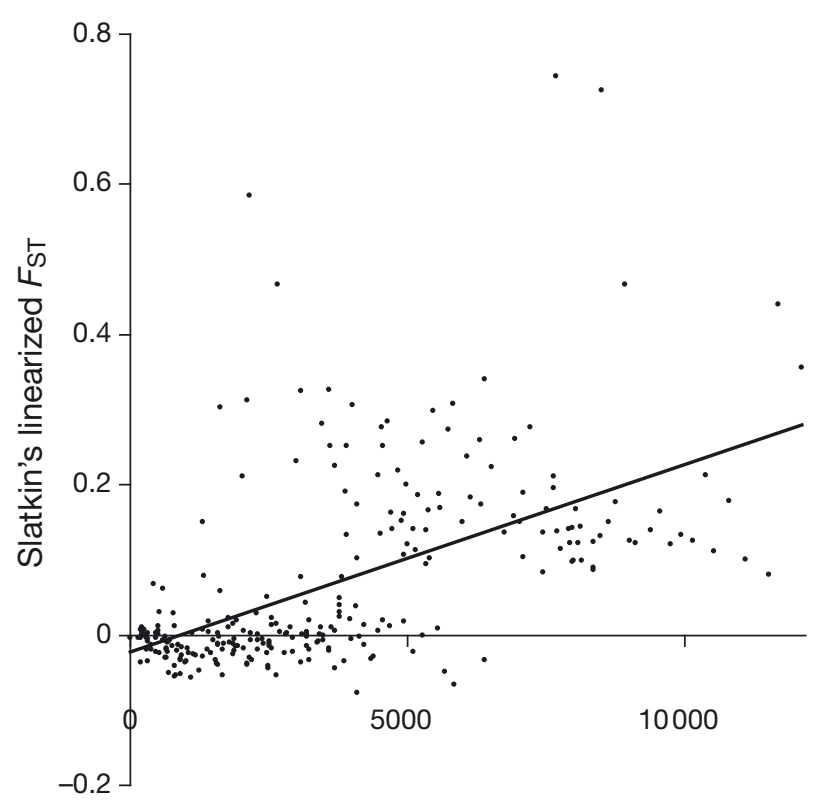

Geographic distance (km)

Fig. 2. Dosidicus gigas. Isolation by distance: Slatkin's linearized pairwise $F_{\mathrm{ST}}$ plotted against linear geographic distance between sites

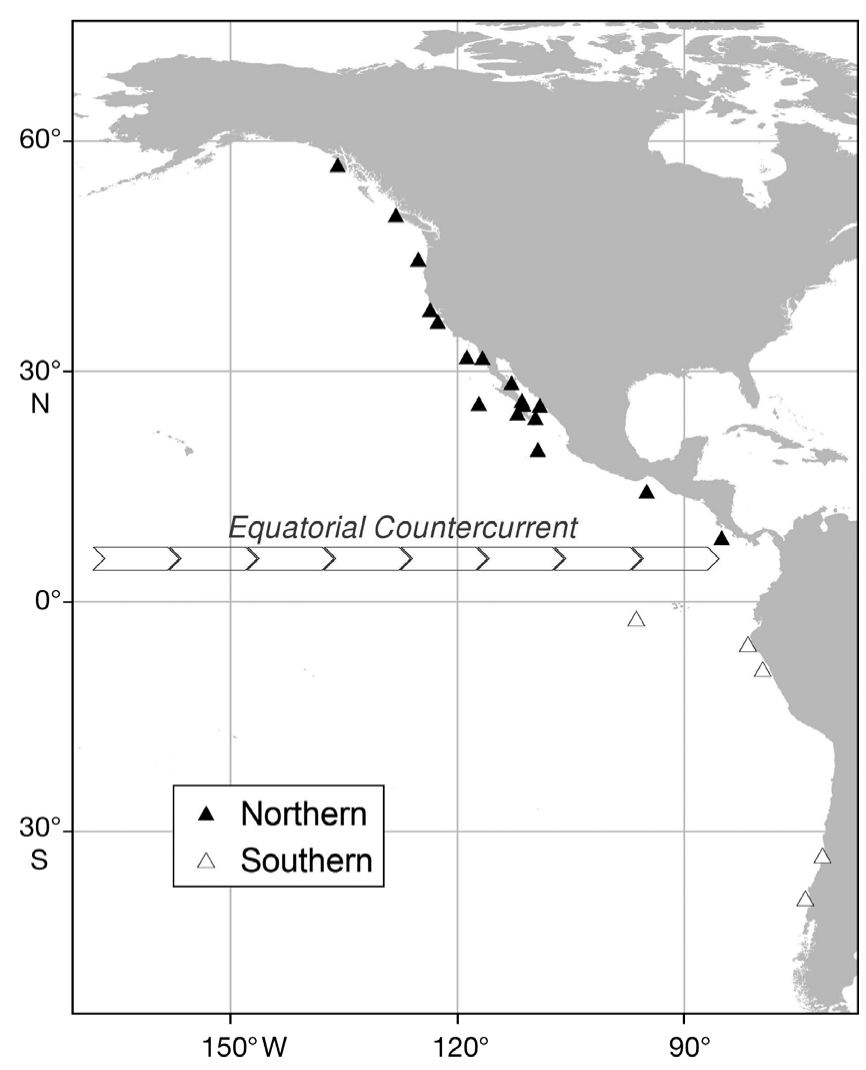

Fig. 3. Dosidicus gigas. Locations of pooled samples. The Equatorial Countercurrent is indicated flowing from west to east. $\Delta$ : northern genetic group; $\Delta$ : southern genetic group (for a mutation rate of $0.7 \%$ ) to $39000 \pm 3000 \mathrm{yr}$ (for a mutation rate of $2.4 \%$ ) before present (mean $\pm \mathrm{SD}$, based on averaging the 4 subsampled runs).

Overall, the sequence data contained 422 haplotypes, of which only 28 occurred in 3 or more individuals. These most common haplotypes were made into a network (Fig. 4) using the program TCS (Clement et al. 2000). The resulting network revealed a clustering of primarily 'southern' and 'northern' haplotypes, but genetic distance between these haplotypes was small ( 1 to 2 nt differences). One branch of 'northern' haplotypes was more deeply divergent than the rest. These divergent haplotypes were found throughout the northern hemisphere, from Canada to Southern Mexico. 'Northern' haplotypes were found in southern samples (black slices in white pies in Fig. 4) less frequently than 'southern' haplotypes were found in northern samples (white slices in black pies in Fig. 4).

From the samples with quantified ML and maturity stage, we found individuals representative of 2 of the 3 size-at-maturity forms in both the northern and southern groups. In the northern group, squid from the 2007 Cordell Bank sampling off California were all of the large size-at-maturity form, whereas squid from the

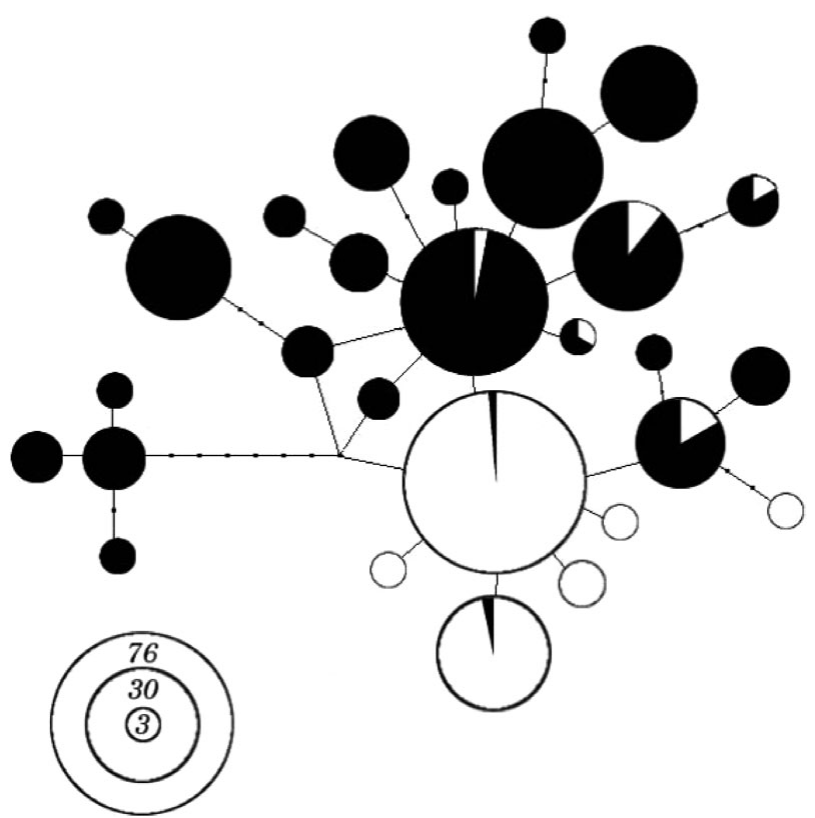

Fig. 4. Dosidicus gigas. Network of the most common haplotypes. Each haplotype is represented by a pie chart. The size of the pie chart indicates the total no. of individuals found with that particular haplotype. Black indicates individuals from northern sampling sites, and white corresponds to southern sites. Each line between haplotypes represents 1 nucleotide change, and small dots indicate 'absent' haplotypes. Thus, 2 haplotypes separated by 3 small dots, and therefore 4 line segments, are separated by 4 nucleotide changes. The 3 circles at the bottom left of the figure are scale circles showing respective numbers of individuals 
Gulf of California in 1999 were all of the medium sizeat-maturity form. In the southern group, squid from the eastern tropical Pacific (ETP) in 2006 were all of the medium size-at-maturity form, and squid from Chile in 2005 were all of the large size-at-maturity form (Table 5). There was no significant pairwise difference between Cordell Bank and Gulf of California samples, or between eastern tropical Pacific and Chile samples (Table 4). We also found no significant partitioning of genetic variation between the large form group (Cordell Bank and Chile) and the small form group (Gulf 1999 and eastern tropical Pacific) with an AMOVA $\left(F_{\mathrm{ct}}=-11.57, \mathrm{p}>0.05\right)$. We found no representatives of the small size-at-maturity form in our sampling.

\section{Sthenoteuthis oualaniensis}

The eastern tropical Pacific specimens were largely identified by the presence of a dorsal photophore in adults (Table 1); juveniles and paralarvae were identified by molecular techniques only. The single centralPacific specimen from 2003 was a mature female of $9.3 \mathrm{~cm} \mathrm{ML}$ with no photophore. Those from 2005 included 8 with a photophore, and 3 without; the ML for 2 of those without were 11.4 and $9.7 \mathrm{~cm}$ (both female). All samples from May 2007 were paralarvae.

Four genetic clades were revealed within Sthenoteuthis oualaniensis (Fig. 5). Pairwise genetic distances between these clades, and within each clade, are provided in Table 6. The most divergent clade corresponds to the early-maturing, dwarf form that lacks the

Table 5. Dosidicus gigas. Mantle length $(\mathrm{ML})($ mean $\pm \mathrm{SD})$ of mature individuals (Stages 4 and 5) from samples representative of 2 size-at-maturity forms from the northern and southern groups. ETP: eastern tropical Pacific

\begin{tabular}{|lcccc|}
\hline Location & Year & $\mathrm{n}$ & $\begin{array}{c}\text { ML } \\
(\mathrm{cm})\end{array}$ & $\begin{array}{c}\text { Size-at-maturity } \\
\text { form }\end{array}$ \\
\hline Mexico & 1999 & 25 & $31.5 \pm 4.1$ & Medium \\
Cordell Bank & 2007 & 16 & $67.6 \pm 4.6$ & Large \\
ETP & 2006 & 79 & $32.8 \pm 3.6$ & $\begin{array}{c}\text { Medium } \\
\text { Large }\end{array}$ \\
Chile '05 & 2005 & 30 & $72.1 \pm 7.4$ & \\
\hline
\end{tabular}

Fig. 5. Sthenoteuthis oualaniensis. Maximum-likelihood phylogeny of $S$. oualaniensis, with Dosidicus gigas as an outgroup, using the General Time Reversible model including a proportion of invariable sites $(\mathrm{GTR}+\mathrm{I})$ of nucleotide substitution. Bootstrap values obtained from 1000 replicates are indicated for each clade. Specimen ID numbers were given according to the collector; the sampling locations of each clade are shown in Fig. 6

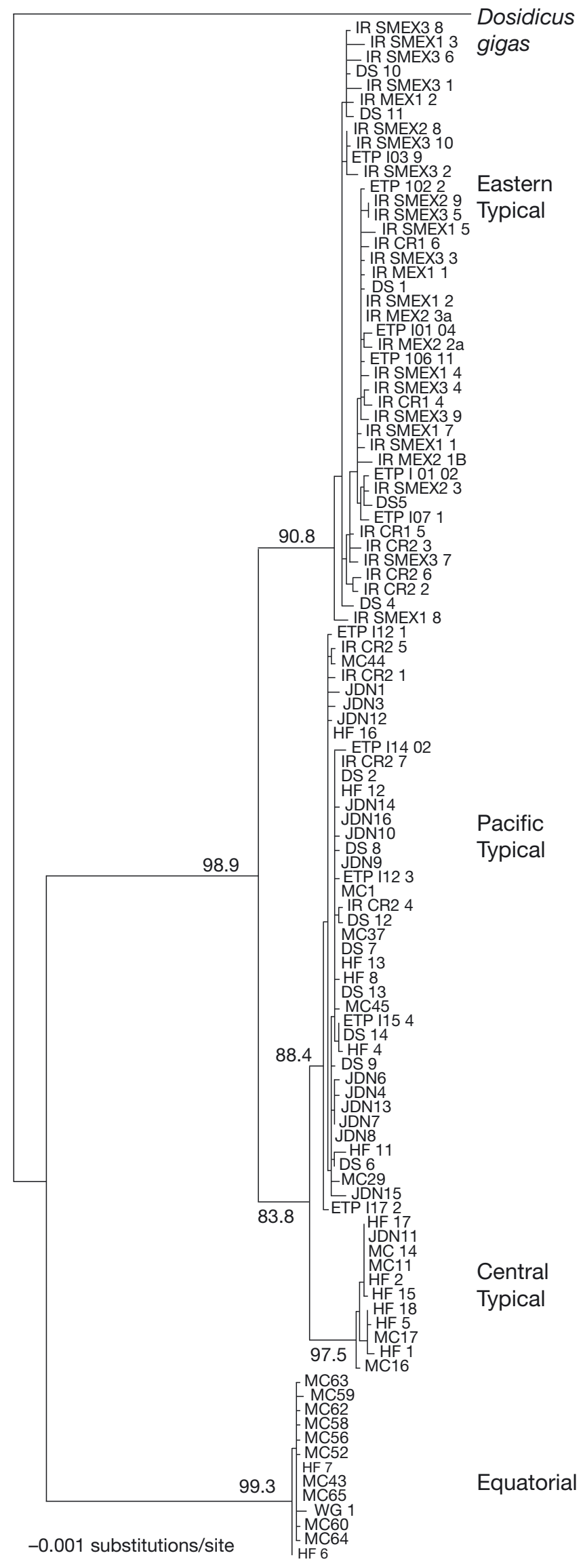


Table 6. Sthenoteuthis oualaniensis. Pairwise genetic distances between and within clades, calculated with Kimura 2P. Genetic distance as percentage $=$ number of (corrected average) pairwise differences divided by total number of loci (1027), multiplied by 100 . Values in bold are significant $(\mathrm{p}<0.05)$

\begin{tabular}{|lcccc|}
\hline & $\begin{array}{c}\text { Pacific } \\
\text { Typical }\end{array}$ & $\begin{array}{c}\text { Central } \\
\text { Typical }\end{array}$ & $\begin{array}{c}\text { Eastern } \\
\text { Typical }\end{array}$ & Equatorial \\
\hline Pacific Typical & 0.310 & & & \\
Central Typical & $\mathbf{1 . 9 9 3}$ & 0.259 & & \\
Eastern Typical & $\mathbf{4 . 2 0 2}$ & $\mathbf{4 . 7 1 6}$ & 0.676 & \\
Equatorial & $\mathbf{1 3 . 5 4 4}$ & $\mathbf{1 4 . 1 1 7}$ & $\mathbf{1 4 . 2 1 1}$ & 0.195 \\
\hline
\end{tabular}

dorsal photophore, possibly Sthenoteuthis sp. nov., as previously suggested (Clarke 1965, Nesis 1993, Yokawa \& Jerez 1999). Individuals from this clade were found only in the central Pacific, south of $6.23^{\circ} \mathrm{N}$, and we refer to it as the Equatorial clade, consistent with the equatorial presence of this morphotype.

The remaining samples form a strongly supported Typical clade, corresponding to the middle-sized, photophore-bearing morphotype of Sthenoteuthis oualaniensis. This clade comprises 3 strongly supported sub-clades. The most divergent of these clades was found only in the eastern Pacific, north of $5.29^{\circ} \mathrm{N}$, and we refer to it as Eastern Typical. The next clade was found only in the central Pacific, north of $6.23^{\circ} \mathrm{N}$; we refer to it as Central Typical. The final clade (Pacific Typical) was found in the central Pacific from Hawaii to the equator but only south of $5.29^{\circ} \mathrm{N}$ in the eastern Pacific (Fig. 6).

Bootstrap analysis with 1000 replicates supports the monophyly of Equatorial (99.3\%), Typical (98.9\%), Eastern Typical (90.8\%), Central plus Pacific Typical (83.8\%), Central Typical (97.5\%), and Pacific Typical (88.4\%) clades (Fig. 5).

Only 1 of the 4 clades, the Pacific Typical, was found in both the eastern and central Pacific. AMOVA of this clade gave a non-significant $F_{\mathrm{ST}}(-0.00273)$, indicating that none of the variation within this clade was accounted for by geography.

\section{DISCUSSION}

\section{Genetics, forms, and morphotypes}

We found no genetic differentiation between medium and large size-at-maturity forms of Dosidicus gigas, in agreement with Yokawa's (1995) evidence from isozymes. This result strongly supports phenotypic plasticity, as proposed by Keyl et al. (2008), rather than species in statu nascendi, as hypothesized by Nigmatullin et al. (2001). Phenotypic plasticity as an expla-

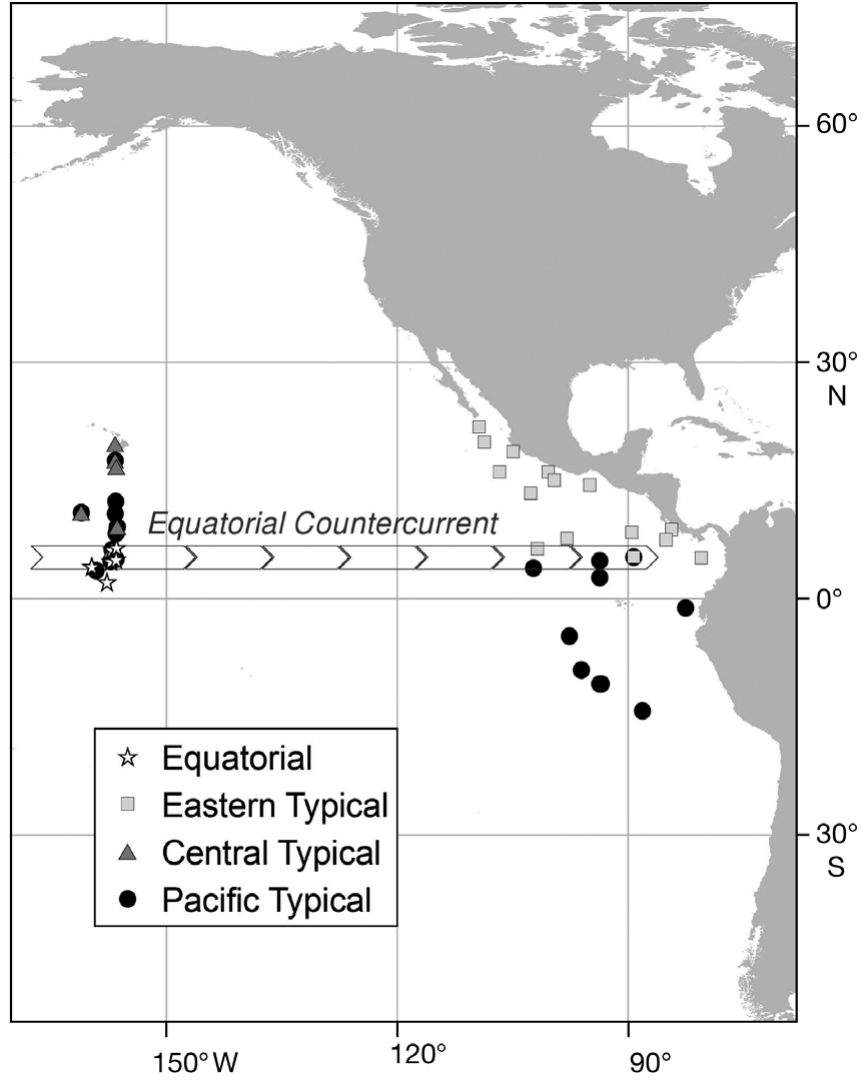

Fig. 6. Sthenoteuthis oualaniensis. Geographic distributions of the 4 clades Equatorial, Eastern Typical, Central Typical and Pacific Typical. The Equatorial Countercurrent is indicated flowing from west to east

nation for the different size forms would be consistent with the finding that the presence and relative abundance of medium and large forms in the Gulf of California may vary according to environmental conditions (Markaida 2006).

Environmental conditions vary temporally, but we found no evidence of temporal genetic variation, even after the strong El Niño of 1999. None of the pairwise comparisons between Gulf of California samples from March or May 1999, October 2004, June, July, November 2005, May, July, or August 2006 were significant. This extends the results of Sandoval-Castellanos et al. (2007), who found no temporal difference between samples taken in 2001 and 2002 off Mazatlán, Mexico, and further supports the hypothesis that phenotypic changes drive temporal variation at any given location.

Our failure to find any representatives of the small size-at-maturity form in the years of collection is intriguing, especially given that the first Dosidicus gigas recorded from the Gulf of California comprised a mature female and male of $21 \mathrm{~cm}$ ML taken in 1959 (Wormuth 1976). Later, Sato (1976) found mated females and mature males of $<24 \mathrm{~cm}$ ML inside the Gulf 
and off southwestern Baja California in 1971. Despite these records, this form is thought to be limited to a narrow band between $12^{\circ} \mathrm{N}$ and 5 to $6^{\circ} \mathrm{S}$, and even within this region it is both rare and patchily distributed. Furthermore, $>70 \%$ of the small size-at-maturity specimens collected in this region were caught in pelagic trawls using very large nets (C. M. Nigmatullin pers. comm.), a method not employed in the present study or (to our knowledge) in any others.

As for Sthenoteuthis oualaniensis, our phylogenetic analysis supports the existence of a morphologically distinct form that is highly genetically divergent (14\%) from all other clades (Equatorial clade, Fig. 5; 99\% bootstrap support). This degree of genetic divergence is near that found between cryptic species of the ommastrephid genus Illex (16 to $25 \%$ with COI, Carlini et al. 2006). Our Equatorial clade likely represents the dwarf, early-maturing, photophore-less Sthenoteuthis sp. nov. that others have suggested (Clarke 1965, see also Nesis 1993, Wormuth 1998, Yokawa \& Jerez 1999). In addition to the absence of the photophore, other differential morphological characteristics have been described (Nesis 1977, Wormuth 1998). This form is restricted to the oligotrophic waters of the equatorial Indian and Pacific Oceans between East Africa and the Galapagos Islands (Nesis 1977, Nigmatullin et al. 1983a). However, in the eastern Pacific it is extremely rare, and its latitudinal range narrows to $1-2^{\circ} \mathrm{S}$ (Nigmatullin et al. 1983a), so it is not surprising that we found no representatives in our sampling of this region.

Although a full description of Sthenoteuthis sp. nov. is beyond the scope of the present study, this genus joins a growing pool of ommastrephids harboring cryptic species. Molecular work has uncovered putative genetic groups within the ommastrephids Illex argentinus (Thorpe et al. 1986, Carvalho et al. 1992, Carlini et al. 2006) and Martialia hyadesi (Brierley et al. 1993), and in each case the authors argued that the groups merited distinction as separate species. Clarifying ommastrephid taxonomy is no mere academic question, as many of these species or species complexes support prominent fisheries.

The discovery of other divergent clades within the typical middle-sized form was an unexpected result. Only 1 middle-sized form, as determined by gladius structure, has been previously recorded in Hawaiian waters (Young \& Hirota 1998), suggesting that the Central Typical clade may be morphologically indistinguishable from the Pacific Typical clade. In the eastern Pacific, however, an early-maturing group of the middle-sized form has been recorded. These individuals possess the dorsal photophore but mature at dwarf sizes, some as small as $9 \mathrm{~cm}$ (Nigmatullin et al. 1983b, Nesis 1993). Could this be the Eastern clade, as illumi- nated by our molecular work? More thorough morphological data must be collected in conjunction with genetic samples to explore this question.

In the Indian Ocean, distinct gladius structures have been found within the middle-sized group of Sthenoteuthis oualaniensis (Nesis 1993). Allozyme electrophoresis, however, suggested that middle-sized forms collected in the extremes of the range (equatorial localities in the Indian Ocean and eastern Pacific), together with the giant form from the Indian Ocean, are probably all the same species (Yokawa \& Jerez 1999). Molecular analysis of $S$. oualaniensis in the form of genetic sequences data from the western part of its range would greatly clarify the population structure of this species. Given the results of the present study, an equally strong clade structure might be expected in western Pacific populations, particularly those associated with archipelagos. In the Indian Ocean, the giant form known from the Arabian Sea may also suggest a complex population structure (Nesis 1977, 1993, Okutani \& Tung 1978).

Curiously, both Dosidicus gigas and Sthenoteuthis oualaniensis exhibit their smallest forms in the region of range overlap, although they are capable of reaching large sizes in other parts of their ranges. Food spectra overlap extensively for $D$. gigas and $S$. oualaniensis in this region (Nigmatullin et al. 2001), suggesting that these 2 species share similar niches and may be competing for resources. Their biogeography may be strongly influenced by such ecological interactions.

\section{North-south genetic break}

A concordant biogeographic break for both ommastrephids at 5 to $6^{\circ} \mathrm{N}$ (Figs. $3 \& 6$ ) was a striking discovery. This finding is consistent with the 2-stock structure proposed for Dosidicus gigas based on migration patterns (Nesis 1983, Wormuth 1976, 1998, Clarke \& Paliza 2000) and with a RAPD analysis of $D$. gigas (Sandoval-Castellanos et al. 2007) that separated 4 sampling locations off North America from 4 sampling locations off South America. Although SandovalCastellanos et al. (2010) did not find robust support for this north-south structure with cytochrome $b$, this is probably explained by low variation in this marker, with only 20 unique haplotypes. Divergence between the 2 populations is likely to be relatively recent, although estimates cover an order of magnitude from 10000 (Sandoval-Castellanos et al. 2007) to $133000 \mathrm{yr}$ (maximum estimate from the present study) before present. In this time frame, it is not surprising that both populations have not diverged more morphologically, as anatomical analysis of $D$. gigas revealed only a 
gradual increase from north to south of the right-arm I (i.e. the dorsal-most arm on the right side of the body) length-index as well as in the number of suckers per arm (Wormuth 1976, 1998). Existence of different populations from equatorial and Peruvian waters, as suggested by differences in ontogenic infection dynamics (Shukhgalter \& Nigmatullin 2001), were not supported by our data.

Separation between the 2 hemispheres could be driven by oceanographic features, which are effective in subdividing oceanic populations and promoting genetic isolation (Norris 2000). Although Dosidicus gigas is found in tropical waters, individual tagged squid in the Gulf of California spend very little time above $25^{\circ} \mathrm{C}$, and residence time in water this warm is extremely short (Davis et al. 2007). In the Gulf, D. gigas of the large form spends most of its time at cooler depths, particularly the upper region of the $\mathrm{OMZ}$ at 200 to $300 \mathrm{~m}$ depth $\left(10\right.$ to $15^{\circ} \mathrm{C}$; Gilly et al. 2006b). This depth range also corresponds to the daytime location of the deep-acoustic scattering layer, a zone rich in the preferred prey of D. gigas (Dunlap 1970, authors' unpubl. data). The OMZ is present throughout the highly productive waters of the eastern Pacific (Fiedler \& Talley 2006) and essentially overlaps with the range of Dosidicus gigas, except in the equatorial region (Fig. 1). This apparent mismatch occurs only because the Equatorial Countercurrent (ECC) brings a finger of warm, oxygenated surface (typically $\sim 27^{\circ} \mathrm{C}$ ) water toward the coast of Central America (Fig. 3) and depresses the OMZ to a greater depth (Fiedler \& Talley 2006). The combination of these features might make the equatorial region less attractive to D. gigas. Although it is unlikely that this would constitute an insurmountable barrier to migration by adult squid, it might provide a meaningful impediment to movements of paralarvae or small juveniles and act to separate 2 populations as they mature, and thereby reduce mixing of reproductively competent squid (Clarke \& Paliza 2000).

Another mechanism acting to isolate southern and northern populations of Dosidicus gigas may arise from seasonality of reproduction. Population differentiation in cetaceans, for example, is frequently driven by opposite reproductive seasonality in northern and southern hemispheres (Hoelzel 1998, Pastene et al. 2007). Data on seasonality and location of spawning by D. gigas are sparse but tantalizing. D. gigas paralarvae and naturally deposited eggs have been identified in the Gulf of California in April, May, and June (Gilly et al. 2006a, Camarillo-Coop \& Salinas Zavala in press, Staaf et al. 2008). None were found in February, the cold season (Camarillo-Coop \& Salinas Zavala in press), although reproductively mature females are found throughout the year in the Gulf of California (Markaida \& Sosa-Nishizaki, 2001). Paralarvae have also been found off the western Baja California peninsula in February, July to August, and October (RamosCastillejos et al. 2010).

Studies in the southern hemisphere are even more limited, but a cruise off the coast of Peru collected paralarvae in November and December (Sakai et al. 2008). Mature adults are found throughout the year, with 2 seasonal peaks (Tafur et al. 2001). These results hint at a potentially opposite seasonality, in which Dosidicus gigas spawn in the spring and summer of whichever hemisphere they inhabit. This could underlie the observed pattern of genetic divergence as suggested by Clarke \& Paliza (2000).

Spawning is clearly possible over a wide range of latitudes, but based on the small degree of genetic divergence within each hemisphere, considerable mixing of reproductive animals must occur. Dosidicus gigas is capable of horizontal migrations at speeds up to $30 \mathrm{~km}$ $\mathrm{d}^{-1}$ (Gilly et al. 2006b). However, stable-isotope analysis has not supported the hypothesis of migrations between regions in the northern hemisphere (RuizCooley et al. 2010). Thus, the extent to which D. gigas takes advantage of its migratory capability is unknown.

Sthenoteuthis oualaniensis also shows a north-south break, similar to that for Dosidicus gigas, between the Pacific Typical and Eastern Typical clades in the east and between the Central Typical and Equatorial clades in the west. This suggests that the ECC may also be influential in impeding genetic mixing in $S$. oualaniensis. It is not known whether this species utilizes the OMZ in the eastern Pacific, although the giant form in the Arabian Sea is associated with the OMZ Nesis (1983).

The overall range of this species is quite different from that of Dosidicus gigas (Fig. 1), but it is possible that only 1 clade (Pacific Typical) is actually distributed throughout this range, while the Eastern Typical and Central Typical clades have more narrow distributions. This may indicate life-history differences between clades, in which long-distance migrations as a means of dispersal or gene flow could play a greater or lesser role. The typical form can perform substantial horizontal migrations (Nesis 1993), as Okutani \& Tung (1978) proposed along the Kuroshio Current. The Eastern Typical and Central Typical clades may be more local groups, limited to the productive regions of the eastern and central Pacific, respectively. Further behavioral, morphological, and genetic data will be needed to elucidate potential stocks within this species, to understand their ecological roles and inform management of the nascent fishery. 
Acknowledgments. This work was supported by funds from the Census of Marine Life (Tagging of Pacific Pelagics), National Science Foundation (OCE 0526640), David and Lucile Packard Foundation, National Geographic Society, California Sea Grant/Ocean Protection Council, and Hopkins Marine Station Marine Life Observatory. Tissue samples were collected and generously shared by J. Ramos (Centro de Investigaciones Biológicas del Noroeste, México), J. Field (NOAA Southwest Fisheries Science Center [SWFSC] Santa Cruz), J. Hoar (Archipelago Marine Research), M. Carpenter (Stanford University), H. Fienberg (Stanford University), C. Yamashiro (Instituto del Mar del Perú), J. Cosgrove and K. Sendall (Royal British Columbia Museum, Canada), M. Pedraza (University of Concepción, Chile), and J. Delafosse. For ship time and support, we are grateful to B. Block (Stanford University), P. Sachs and the crew of the SSV 'Robert C. Seamans', J. O'Sullivan (Monterey Bay Aquarium), as well as L. Ballance, J. Barlow, R. L. Pitman, A. Henry (NOAA SWFSC La Jolla), and the crew of the 'David Starr Jordan' and the 'MacArthur II'. Maps were made with the assistance of A. Booth (Stanford and Moss Landing Marine Labs). We thank S. Palumbi, C. Hanifin, A. Haupt, J. Ladner, M. Pinsky, and T. Oliver (Stanford) for guidance and advice on molecular data analysis. Discussions with L. Zeidberg (UCLA), C. Reeb (Stanford), and C. Nigmatullin (AtlantNIRO) aided our interpretation of results. The criticism of 3 anonymous reviewers greatly improved the manuscript.

\section{LITERATURE CITED}

Brierley AS, Rodhouse PG, Thorpe JP, Clarke MR (1993) Genetic evidence of population heterogeneity and cryptic speciation in the ommastrephid squid Martialia hyadesi from the Patagonia Shelf and Antarctic Polar Frontal Zone. Mar Biol 116:593-602

Camarillo-Coop S, Salinas-Zavala C, Manzano-Sarabia M, Aragón-Noriega EA (in press) Presence of Dosidicus gigas paralarvae (Cephalopoda: Ommastrephidae) in the central Gulf of California, Mexico related to oceanographic conditions. J Mar Biol Assoc UK

Carlini DB, Kunkle LK, Vecchione M (2006) A molecular systematic evaluation of the squid genus Illex (Cephalopoda: Ommastrephidae) in the North Atlantic Ocean and Mediterranean Sea. Mol Phylogenet Evol 41:496-502

Carvalho GR, Thompson A, Stoner AL (1992) Genetic diversity and population differentiation in the shortfin squid (Illex argentinus) in the south-west Atlantic. J Exp Mar Biol Ecol 158:105-121

Clarke M (1965) Large light organs on the dorsal surfaces of the squids Ommastrephes pteropus, 'Symplectoteuthis oualaniensis' and 'Dosidicus gigas'. Proc Malacol Soc Lond 36:319-321

Clarke M (1966) A review of the systematics and ecology of oceanic squids. Adv Mar Biol 4:147-187

Clarke R, Paliza O (2000) The Humboldt current squid Dosidicus gigas (Orbigny, 1835). Rev Biol Mar Oceanogr 35:1-38

Clement M, Posada D, Crandall K (2000) TCS: a computer program to estimate gene genealogies. Mol Ecol 9: 1657-1660

Cosgrove JA (2005) The first specimens of Humboldt squid in British Columbia. PICES Press 13:30-31

Davis RW, Jaquet N, Gendron D, Markaida U, Bazzino G, Gilly W (2007) Diving behavior of sperm whales in relation to behavior of a major prey species, the jumbo squid, in the Gulf of California, Mexico. Mar Ecol Prog Ser 333: 291-302
Donald KM, Kennedy M, Spencer HG (2005) Cladogenesis as the result of long-distance rafting events in South Pacific topshells (Gastropoda, Trochidae). Evolution 59: 1701-1711

Dunlap CR (1970) A reconnaissance of the deep scattering layers in the eastern tropical Pacific and the Gulf of California. In: Farquhar GB (ed) Proc Int Symp Biol Sound Scattering in the Ocean, 31 Mar to 2 Apr 1970, Warrenton, VA. Report 005. Maury Center for Ocean Science, Washington, DC, p 395-408

Dunning M (1998) A review of the systematics, distribution and biology of the arrow squid genera Ommastrephes Orbigny, 1835, Sthenoteuthis Verrill, 1880, and Ornithoteuthis Okada, 1927 (Cephalopoda, Ommastrephidae). In: Voss NA, Vecchione M, Toll RB, Sweeney MJ (eds) Systematics and biogeography of cephalopods. Smithson Contrib Zool 586(II):425-433

Ersts PJ (2009) Geographic Distance Matrix Generator (version 1.2.3). American Museum of Natural History, Center for Biodiversity and Conservation. Available at: http://biodiversityinformatics.amnh.org/open_source/gdmg (accessed 4 Dec 2009)

> Excoffier L, Laval G, Schneider S (2005) Arlequin (version 3.0): an integrated software package for population genetics data analysis. Evol Bioinform Online 1:47-50

FAO (2010) Total fishery production. Fishstat Plus, 19502008, v. 2.3. Food and Agriculture Organization of the United Nations. Available at http://www.fao.org/fishery/ statistics/software/fishstat/en

> Fiedler PC, Talley LD (2006) Hydrography of the eastern tropical Pacific: a review. Prog Oceanogr 69:143-180

> Folmer O, Black M, Hoeh W, Lutz R, Vrijenhoek R (1994) DNA primers for amplification of mitochondrial cytochrome c oxidase subunit I from diverse metazoan invertebrates. Mol Mar Biol Biotechnol 3:294-299

Garcia HE, Locarnini RA, Boyer TP, Antonov JI (2006) World ocean atlas 2005, Vol 4: nutrients (phosphate, nitrate, silicate). In: Levitus S (ed) NOAA atlas NESDIS 64. US Government Printing Office, Washington, DC

Gilly WF, Elliger CA, Salinas CA, Camarilla-Coop S, Bazzino G, Beman M (2006a) Spawning by jumbo squid Dosidicus gigas in San Pedro Mártir Basin, Gulf of California, Mexico. Mar Ecol Prog Ser 313:125-133

Gilly WF, Markaida U, Baxter CH, Block BA and others (2006b) Vertical and horizontal migrations by the jumbo squid Dosidicus gigas revealed by electronic tagging. Mar Ecol Prog Ser 324:1-17

Guindon S, Gascuel O (2003) PhyML - a simple, fast, and accurate algorithm to estimate large phylogenies by maximum likelihood. Syst Biol 52:696-704

Hellberg ME, Vacquier VD (1999) Rapid evolution of fertilization selectivity and lysin cDNA sequences in teguline gastropods. Mol Biol Evol 16:839-848

Hey J, Nielsen R (2004) Multilocus methods for estimating population sizes, migration rates and divergence time, with applications to the divergence of Drosophila pseudoobscura and D. persimilis. Genetics 167:747-760

Hoelzel AR (1998) Genetic structure of cetacean populations in sympatry, parapatry, and mixed assemblages: implications for conservation policy. J Hered 89: 451-458

Keyl F, Argüelles J, Mariátegui L, Tafur R, Wolff M, Yamashiro C (2008) A hypothesis on range expansion and spatio-temporal shifts in size-at-maturity of jumbo squid (Dosidicus gigas) in the Eastern Pacific Ocean. CCOFI Rep 49:119-128

Kimura M (1980) A simple method for estimating evolutionary 
rate of base substitutions through comparative studies of nucleotide sequences. J Mol Evol 16:111-120

Lipiński MR, Underhill LG (1995) Sexual maturation in squid: quantum or continuum? S Afr J Mar Sci 15:207-223

Mantel N (1967) The detection of disease clustering and a generalized regression approach. Cancer Res 27: 209-220

Markaida U (2006) Population structure and reproductive biology of jumbo squid Dosidicus gigas from the Gulf of California after the 1997-1998 El Niño event. Fish Res 79: 28-37

Markaida U, Sosa-Nishizaki O (2001) Reproductive biology of jumbo squid Dosidicus gigas in the Gulf of California, 1995-1997. Fish Res 54:63-82

Markaida U, Quiñonez-Velazquez C, Sosa-Nishizaki O (2004) Age, growth and maturation of jumbo squid Dosidicus gigas (Cephalopoda: Ommastrephidae) from the Gulf of California, Mexico. Fish Res 66:31-47

Marko PB (2002) Fossil calibration of molecular clocks and the divergence times of geminate species pairs separated by the Isthmus of Panama. Mol Biol Evol 18:2005-2021

Nesis KN (1977) Population structure of the squid Sthenoteuthis oualaniensis (Lesson 1930) (Ommastrephidae) in the tropical Western Pacific. Trudy Inst Okeanol 107: 15-29 (in Russian)

Nesis KN (1983) Dosidicus gigas. In: Boyle PR (ed) Cephalopod life cycles, Vol 1. Species accounts. Academic Press, London, p 216-231

Nesis KN (1993) Population structure of oceanic Ommastrephids, with particular reference to Sthenoteuthis oualaniensis: a review. In: Okutani K, O'Dor RK, Kubodera $\mathrm{T}$ (eds) Recent advances in cephalopod fisheries biology. Tokai University Press, Tokyo, p 293-312

Nigmatullin CM, Tsygankov VY, Sabirov RM (1983a) On the taxonomic status of the early-maturing and late-maturing forms of the squid Sthenoteuthis oualaniensis (Lesson). In: Starobogatov YaI, Nesis KN (eds) Taxonomy and ecology of cephalopods. Zoological Institute of Academy of Sciences USSR, Leningrad, p 94-96 (in Russian)

Nigmatullin CM, Sabirov RM, Tsygankov VY, Schetinnikov SA (1983b) Reproductive biology of squids Sthenoteuthis oualaniensis Lesson and Dosidicus gigas (d'Orbigny) in the eastern tropical Pacific. In: Starobogatov YaI, Nesis KN (eds) Taxonomy and ecology of cephalopods. Zoological Institute of Academy of Sciences USSR, Leningrad, p 122-124 (in Russian)

Nigmatullin CM, Nesis KN, Arkhipkin AI (2001) Biology of the jumbo squid Dosidicus gigas (Cephalopoda: Ommastrephidae). Fish Res 54:9-19

> Norris RD (2000) Pelagic species diversity, biogeography, and evolution. Paleobiology 26(Suppl):236-258

Okutani T, Tung I (1978) Reviews of biology of commercially important squids in Japanese and adjacent waters. Veliger 21:87-94

> Pastene LA, Goto M, Kanda N, Zerbini AN and others (2007) Radiation and speciation of pelagic organisms during periods of global warming: the case of the common minke whale, Balaenoptera acutorostrata. Mol Ecol 16: 1481-1495

Posada D (2008) jModelTest: phylogenetic model averaging. Mol Biol Evol 25:1253-1256

Ramos-Castillejos JE, Salinas-Zavala CE, Camarillo-Coop S, Enríquez-Paredes LM (2010) Paralarvae of the jumbo squid, Dosidicus gigas. Invertebr Biol 129:172-183

Rodríguez F, Oliver JF, Marín A, Medina JR (1990) The general stochastic model of nucleotide substitution. J Theor Biol 142:485-501
Roper CFE, Sweeny MJ, Nauen CE (1984) Cephalopods of the world: an annotated and illustrated catalogue of species of interest to fisheries. FAO Species Catalogue, Vol 3. FAO Species Synop 125. FAO, Rome

Ruiz-Cooley RI, Villa EC, Gould WR (2010) Ontogenetic variation of $\delta^{13} \mathrm{C}$ and $\delta^{15} \mathrm{~N}$ recorded in the gladius of the jumbo squid Dosidicus gigas: geographic differences. Mar Ecol Prog Ser 399:187-198

Sakai M, Mariátegui L, Wakabayashi T, Yamashiro C, Tuchiya K (2008) Distribution and abundance of jumbo flying squid paralarvae (Dosidicus gigas) off Perú and in waters west of the Costa Rica Dome during the 2007 La Niña. Acuña E, Cubillos L, Ibanez C (eds) 4th Int Symp Pacific Squids, 28 Nov to 2 Dec 2008. Universidad Catolica del Norte, Coquimbo, p 95-97

Sandoval-Castellanos E, Uribe-Alcocer M, Díaz-Jaimes P (2007) Population genetic structure of jumbo squid (Dosidicus gigas) evaluated by RAPD analysis. Fish Res 83:113-118

Sandoval-Castellanos E, Uribe-Alcocer M, Díaz-Jaimes P (2010) Population genetic structure of the Humboldt squid (Dosidicus gigas d'Orbigny, 1835) inferred by mitochondrial DNA analysis. J Exp Mar Biol Ecol 385:73-78

Sato T (1976) Results of exploratory fishing for Dosidicus gigas (D'Orbigny) off California and Mexico. FAO Fish Rep 170(Suppl 1):61-67

Shukhgalter OA, Nigmatullin CM (2001) Parasitic helminths of the jumbo squid Dosidicus gigas (Cephalopoda: Ommastrephidae) in open waters of the central east Pacific. Fish Res 54:95-110

Slatkin M (1995) A measure of population subdivision based on microsatellite allele frequencies. Genetics 139:457-462

Snÿder R (1998) Aspects of the biology of the giant form of Sthenoteuthis oualaniensis Cephalopoda: Ommastrephidae) from the Arabian Sea. J Molluscan Stud 64:21-34

Sokal R, Rohlf FJ (1995) Biometry. WH Freeman, New York, NY

Staaf DJ, Camarillo-Coop S, Haddock SHD, Nyack AC and others (2008) Natural egg mass deposition by the Humboldt squid (Dosidicus gigas) in the Gulf of California and characteristics of hatchlings and paralarvae. J Mar Biol Assoc UK 88:759-770

Tafur R, Villegas P, Rabí M, Yamashiro C (2001) Dynamics of maturation, seasonality of reproduction and spawning grounds of the jumbo squid Dosidicus gigas (Cephalopoda: Ommastrephidae) in Peruvian waters. Fish Res 54: $33-50$

- Tamura K, Nei M (1993) Estimation of the number of nucleotide substitutions in the control region of mitochondrial DNA in humans and chimpanzees. Mol Biol Evol 10: 512-526

Thorpe JP, Havenhand JN, Patterson K (1986) Report of the University of Liverpool (Department of Marine Biology) to the Falkland Islands Developmental Corporation. Stock and species identity of the Patagonian Shelf Illex. Falkland Islands Developmental Corporation, Port Stanley

Weir BS (1996) Genetic data analysis II: methods for discrete population genetic data. Sinauer Associates, Sunderland, MA, p 91-139

Weir BS, Cockerham CC (1984) Estimating F-statistics for the analysis of population structure. Evolution 38: $1358-1370$

Wing BL (2006) Unusual invertebrates and fish observed in the Gulf of Alaska, 2004-2005. PICES Press 14:26-28

Wormuth JH (1976) The biogeography and numerical taxonomy of the oegopsid squid family Ommastrephidae in the Pacific Ocean. Bull Scripps Inst Oceanogr 23 
Wormuth JH (1998) Workshop deliberations on the Ommastrephidae: a brief history of their systematics and a review of the systematics, distribution and biology of the genera Martialia Rochebrune and Mabille, 1889, Todaropsis Girard, 1890, Dosidicus Steenstrup, 1857, Hyaloteuthis Gray, 1849 and Eucleoteuthis Berry, 1916. In: Voss NA, Vecchione M, Toll RB, Sweeney MJ (eds) Systematics and biogeography of cephalopods. Smithson Contrib Zool 586: 373-383

Xinjun C, Bilin L, Siquan T, Weiguo Q, Xiaohu Z (2007) Fishery biology of purpleback squid, Sthenoteuthis oualaniensis, in the northwest Indian Ocean. Fish Res 83:98-104

Yokawa K (1995) Isozyme comparison of large, medium and small size specimens of Dosidicus gigas. Proc Res Conf Squid Resourc Fish Cond Hachinohe, 1993, p 48-52 (in Japanese). Available at http://jsnfri.fra.affrc.go.jp/shigen/ ika_kaigi/contents/H5/H5-8.pdf

Yokawa K, Jerez B (1999) Estudios preliminares en la estructura genética bioquímica del calamar púrpura (Sthenoteuthis oualaniensis) en el Indico norte y el océano Pací-

Editorial responsibility: Philippe Borsa, Montpellier, France fico sur. In: Avances en métodos y tecnología aplicados a la investigación pesquera. Seminario final del proyecto INIDEP-JICA sobre evaluación y monitoreo de recursos pesqueros (1994-1999). Instituto Nacional de Investigación y Desarrollo Pesquero, Mar del Plata, p 185-187 (in Spanish with English abstract)

Yokobori S, Fukuda N, Nakamura M, Aoyama T, Oshima T (2004) Long-term conservation of six duplicated structural genes in cephalopod mitochondrial genomes. Mol Biol Evol 21:2034-2046

Young RE, Hirota J (1998) Review of the ecology of Sthenoteuthis oualaniensis near the Hawaiian Archipelago. In: Okutani T (ed) Contributed papers to international symposium on large pelagic squids. Japan Marine Fishery Resources Research Center, Tokyo, p 131-143

Zuyev G, Nigmatullin C, Chesalin M, Nesis K (2002) Main results of long-term worldwide studies on tropical nektonic oceanic squid genus Sthenoteuthis: an overview of the Soviet investigations. Bull Mar Sci 71: 1019-1060

Submitted: January 4, 2010; Accepted: September 15, 2010 Proofs received from author(s): November 10, 2010 